\title{
APLIKASI ARDUINO DAN REMOTE DESKTOP UNTUK PRAKTIK SOGI JARAK JAUH
}

\author{
Muhammad Said Al Manshury ${ }^{1 *}$ \\ ${ }^{1}$ PT PLN (Persero) \\ Unit Pelaksana Pendidikan dan Pelatihan (UPDL) Semarang \\ ${ }^{*}$ Penulis korespondensi, E-mail: m.said@pln.co.id
}

\begin{abstract}
Abstrak
Pandemi COVID-19 menyebabkan pembelajaran belum dapat dilakukan secara tatap muka. Pembelajaran yang hanya berisi teori tanpa praktik, dapat dilakukan menggunakan aplikasi video conference seperti zoom, google meet, dan lainlain. Sedangkan untuk pembelajaran yang mengandung praktik, seperti pembelajaran SOGI (Sistem Otomasi Gardu Induk) tidak optimal jika hanya menggunakan video conference. Untuk itu diperlukan solusi untuk permasalahan tersebut. Salah satu solusi yang belum pernah diterapkan sebelumnya di UPDL Semarang adalah dengan mengkombinasikan aplikasi arduino dengan aplikasi remote desktop, di mana aplikasi arduino digunakan sebagai antar muka untuk mengontrol peralatan SOGI, sedangkan aplikasi remote desktop digunakan untuk memonitor dan mengontrol peralatan SOGI secara jarak jauh. Aplikasi arduino dibangun dengan hardware arduino, software arduino dan software Visual Basic, sedangkan aplikasi remote desktop menggunakan anydesk atau aplikasi yang sejenis. Hardware yang diperlukan untuk praktik secara jarak jauh ini meliputi : arduino, button pusher, webcam, dan komputer. Hasil yang diperoleh dengan menerapkan aplikasi arduino dan remote desktop ini adalah para peserta pembelajaran dari luar UPDL Semarang dapat mengoperasikan peralatan SOGI secara jarak jauh dengan tingkat keberhasilan $100 \%$ yaitu dapat mengoperasikan 10 tombol dan melihat tampilan LCD peralatan SOGI, sehingga praktik SOGI bisa dilakukan jarak jauh.
\end{abstract}

\section{Kata kunci: Arduino, Remote Desktop, Sistem Otomasi Gardu Induk}

\begin{abstract}
COVID-19 pandemic causes In Class Training can not be done. Learning that only contains theory without practice, it can be done by using video conference applications such as zoom, google meet, etc. But learning that contains practice, such as SAS (Substation Automation System), is not optimal if only using video conference. It's needed a solution to overcome this problem. Solution that has never been implemented at UPDL Semarang is to combine the arduino application with a remote desktop application, the arduino application is used as an interface to access SOGI equipment, and the remote desktop application is used to monitor and control SOGI equipment remotely. Arduino applications are built with arduino hardware, arduino software and Visual Basic software. And for the remote desktop application uses anydesk or similar applications. Hardwares for this application are : arduino, button pusher, webcam and computer. By implementing the arduino and remote desktop application, participants from outside UPDL Semarang can operate SAS equipment remotely with $100 \%$ success rate, they can operate 10 buttons and monitor the LCD display of SAS equipment, so the practice of SAS can be done remotely.
\end{abstract}

Keywords: Arduino, Remote Desktop, Substation Automation System (SAS)

\section{Pendahuluan}

PT. PLN (Persero) memiliki Pusat Pendidikan dan Pelatihan (PUSDIKLAT) yang digunakan untuk melakukan pendidikan dan pelatihan bagi pegawai dan calon pegawai PLN. Salah satu unit dari PUSDIKLAT adalah UPDL Semarang (Unit Pendidikan dan Pelatihan Semarang), yang fokus pada bidang transmisi, termasuk di dalamnya adalah tentang Sistem Otomasi Gardu Induk (SOGI) [1]. Pada kondisi normal, sebelum terjadi pandemi COVID-19, pembelajaran dilakukan secara tatap muka di kelas (In Class Training), baik itu pembelajaran yang hanya berisi teori ataupun pembelajaran yang berisi teori dan praktik. Pada saat terjadi pandemi COVID-19, pembelajaran tidak dapat dilakukan secara tatap muka, termasuk pembelajaran yang berisi praktik. Untuk pembelajaran yang hanya berisi teori tanpa praktik, dapat dilakukan menggunakan aplikasi video conference seperti zoom, google meet, microsoft teams, cisco webex dan lainlain. Sedangkan untuk pembelajaran yang mengandung praktik, seperti pembelajaran SOGI (Sistem Otomasi Gardu Induk) tidak optimal jika hanya menggunakan video conference. Pada pembelajaran praktik SOGI, peserta harus dapat mengoperasikan peralatan SOGI. 
Pengoperasian peralatan SOGI ini dilakukan dengan menggunakan tombol dan tampilan LCD yang ada pada peralatan SOGI. Salah satu solusi yang belum pernah diterapkan sebelumnya di UPDL Semarang adalah dengan mengkombinasikan aplikasi arduino dengan aplikasi remote desktop. Solusi ini merupakan kombinasi hardware dan software [2] Peralatan laboratorium berbasis arduino merupakan alternatif solusi yang berbiaya murah [3] dan interaktif [4]. Selain itu peralatan laboratorium berbasis arduino ini menawarkan kontrol sistem laboratorium yang inovatif [5] dan juga berbasis open source hardware [6] yang dapat melakukan kontrol dan akuisisi data [7]. Arduino ini banyak digunakan untuk platform pendidikan [8] dan pembelajaran [9].

\section{Metode}

\subsection{Metode Penelitian}

Metode yang digunakan dalam penelitian ini adalah dengan melakukan uji coba secara langsung di laboratorium SCADA pada UPDL Semarang, yaitu pada peralatan SOGI (Sistem Otomasi Gardu Induk). Sebelum melakukan uji coba, dilakukan kajian literatur untuk mencari teknologi yang dapat diterapkan untuk praktik SOGI jarak jauh. Berdasarkan kajian literatur, teknologi yang digunakan untuk praktik SOGI jarak jauh ini adalah menggunakan kombinasi aplikasi arduino dan remote desktop, di mana aplikasi arduino digunakan sebagai antar muka untuk mengontrol peralatan SOGI, sedangkan aplikasi remote desktop digunakan untuk memonitor dan mengontrol peralatan SOGI secara jarak jauh. Remote desktop memungkinkan pengguna mengakses komputer secara jarak jauh [10]. Aplikasi remote desktop dapat digunakan baik di dunia kerja maupun dunia pendidikan [11]. Salah satu hal yang perlu diperhatikan dalam penggunaan aplikasi remote desktop adalah perlindungan terhadap data yang penting [12].

\subsection{Desain Teknis}

Peralatan SOGI yang akan dikontrol dan yang akan dimonitor secara jarak jauh dapat dilihat pada gambar 1 .

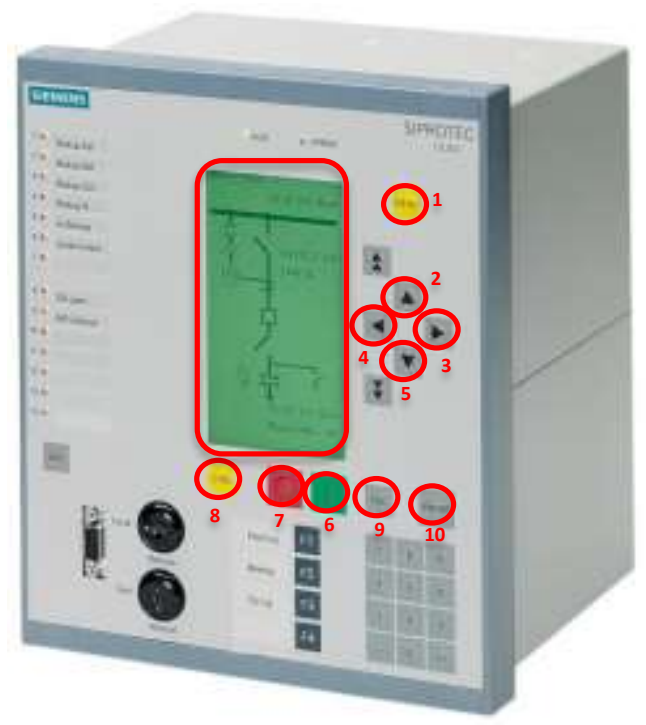

Gambar 1. Peralatan SOGI yang akan dikontrol dan dimonitor secara jarak jauh

Pada gambar 1 dapat dilihat bahwa peralatan SOGI yang akan dikontrol secara jarak jauh meliputi 10 tombol yaitu:
1. Tombol MENU
2. Tombol UP
3. Tombol RIGHT
4. Tombol LEFT
5. Tombol DOWN
6. Tombol CLOSE
7. Tombol OPEN
8. Tombol CTRL
9. Tombol ESC
10. Tombol ENTER

Sedangkan bagian peralatan SOGI yang akan dimonitor adalah tampilan LCD.

Pada peralatan SOGI terdapat banyak tombol, tetapi yang akan dikontrol hanya 10 tombol saja. Sedangkan untuk desain praktik SOGI jarak jauh dapat dilihat pada gambar 2 di bawah ini. 


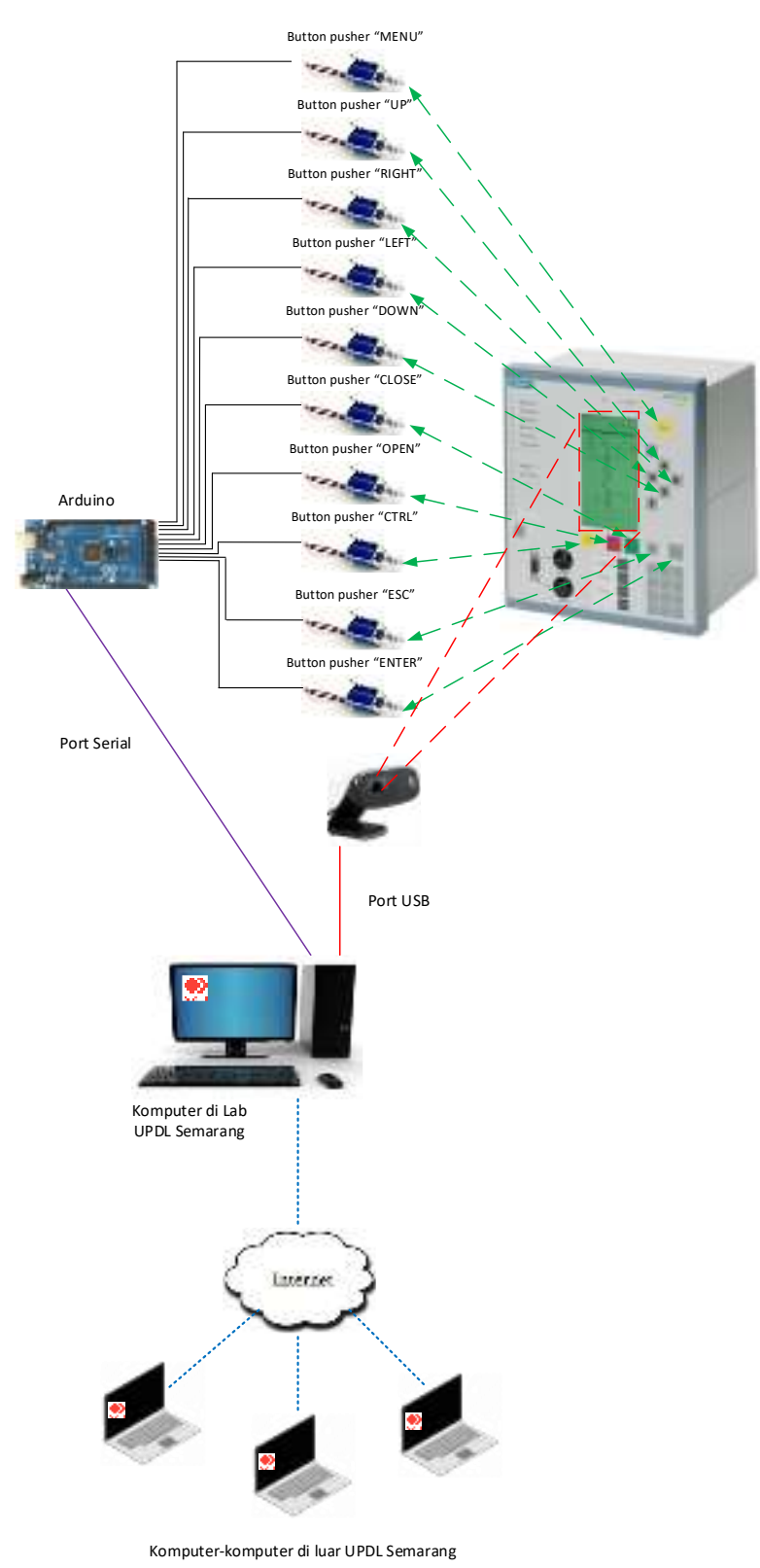

Gambar 2. Desain praktik SOGI jarak jauh

Pada Gambar 2 dapat dilihat bahwa pada desain praktik SOGI jarak jauh ini menggunakan 10 button pusher yang akan digunakan untuk menekan tombol pada peralatan SOGI. Masing-masing button pusher ini ditempatkan di depan tombol-tombol peralatan SOGI, dan terkoneksi ke terminal/pin output arduino, sehingga jika ada perintah dari arduino maka button pusher ini akan menekan tombol yang sudah ditentukan. Dengan kata lain button pusher inilah yang menggantikan tangan manusia. Button pusher ini dikontrol melalui arduino. Arduino dapat terhubung secara serial ke komputer [13] seperti pada gambar 2, di mana di komputer dipasang aplikasi Visual Basic. Visual Basic adalah salah satu bahasa pemrograman yang dapat digunakan untuk simulasi [14]. Dalam beberapa tahun terakhir, platform terbuka mikrokontroler dan bahasa pemrograman visual telah mendapatkan banyak perhatian [15]. Aplikasi Visual Basic tersebut berisi tombol virtual, yang merepresentasikan dari tombol-tombol yang akan ditekan. Jika salah satu tombol virtual ditekan, maka aplikasi Visual Basic akan mengirimkan perintah ke arduino supaya button pusher menekan tombol pada peralatan SOGI. Selain tombol virtual, aplikasi Visual Basic dilengkapi dengan video yang menayangkan tampilan LCD peralatan SOGI (via webcam), sehingga peserta pembelajaran dapat melihat hasil eksekusi dari tombol yang ditekan. Supaya komputer di laboratorium UPDL Semarang dapat diakses dari tempat lain, maka komputer UPDL Semarang dan komputer peserta pembelajaran harus diinstall aplikasi remote desktop (seperti anydesk) dan juga harus terkoneksi ke internet. Berikut ini kebutuhan hardware, software dan media komunikasi untuk praktik SOGI jarak jauh.

Kebutuhan hardware praktik SOGI jarak jauh :

- Arduino 1 buah

- Button pusher 10 buah

- Webcam 1 buah

- Komputer 1 buah

Kebutuhan software praktik SOGI jarak jauh :

- Program Arduino

- Visual Basic

- Remote Desktop (Anydesk)

Kebutuhan media komunikasi praktik SOGI jarak jauh :

- Hardwired/kabel : untuk koneksi arduino dengan button pusher

- Serial : untuk komunikasi komputer dengan arduino)

- Port USB : untuk komunikasi komputer dengan webcam

- Internet : untuk aplikasi remote desktop

\subsection{Flowchart Program}

Program yang perlu dibuat untuk praktik SOGI jarak jauh ini ada 2 yaitu program arduino dan Visual Basic. Aplikasi arduino digunakan sebagai antar muka untuk mengontrol peralatan SOGI melalui button pusher. Sedangkan program Visual Basic berisi 10 tombol virtual yang digunakan untuk memberikan perintah ke arduino. Tombol virtual tersebut mewakili 10 tombol peralatan SOGI yang akan dikontrol secara jauh. Selain itu program Visual Basic digunakan untuk menayangkan video tampilan LCD peralatan SOGI yang diambil melalui webcam. Dengan adanya video tampilan LCD ini, peserta pembelajaran praktik SOGI dapat melihat kondisi peralatan SOGI secara real time dari jarak jauh.

Flowchart dari program arduino dan Visual Basic dapat dilihat pada gambar 3 dan gambar 4. 


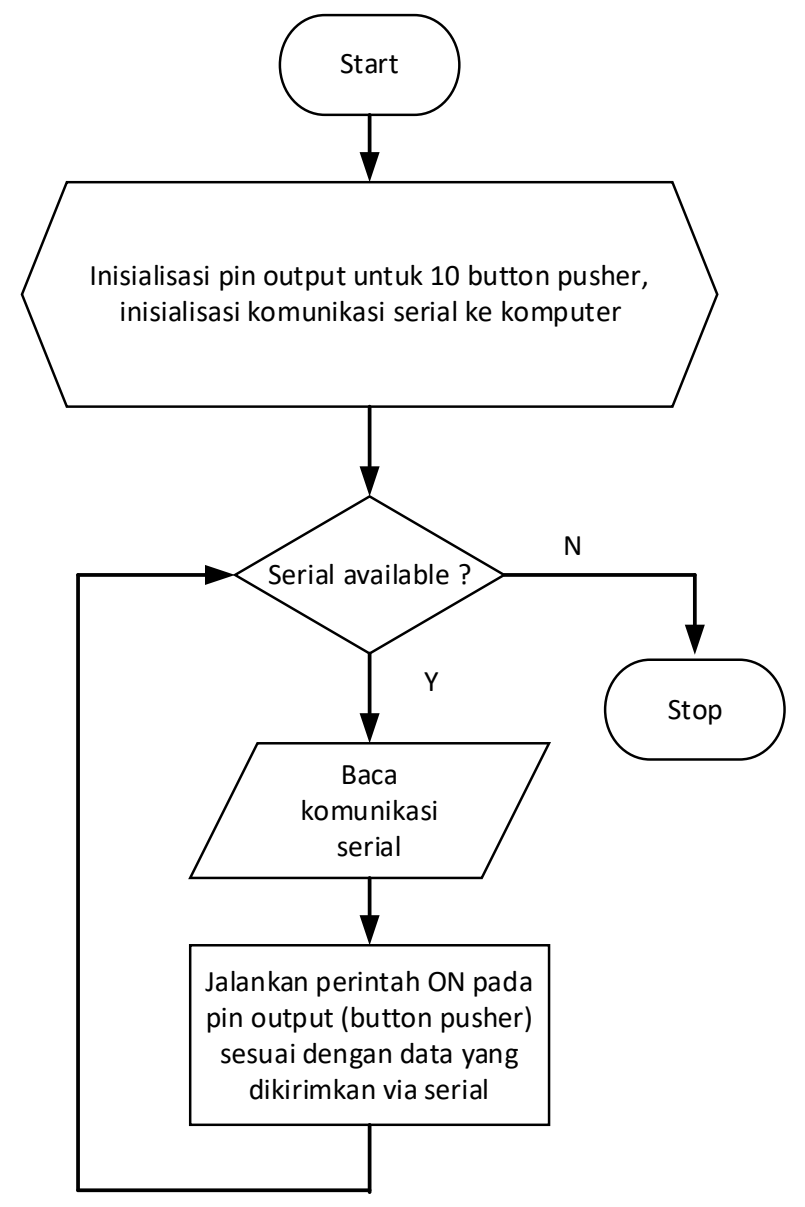

Gambar 3. Flowchart Program Arduino

Gambar 3 merupakan flowchart dari program arduino. Program arduino ini berfungsi untuk mengontrol beberapa button pusher melalui komputer via komunikasi serial. Program arduino ini diawali dengan inisialisasi pin output untuk 10 button pusher dan juga inisialisasi komunikasi serial. Lalu program arduino akan berjalan secara terus menerus selama komunikasi serial dalam kondisi available. Program arduino akan membaca komunikasi serial dan menjalankan perintah ON pada button pusher sesuai dengan data yang dikirimkan via serial. Sebagai contoh, misalnya dari komunikasi serial diperoleh data untuk melakukan kontrol pada tombol "MENU", maka arduino akan memberikan perintah $\mathrm{ON}$ pada button pusher yang ditempatkan di depan tombol "MENU", sehingga tombol "MENU" akan ditekan oleh button pusher tersebut.

Gambar 4 merupakan flowchart dari program Visual Basic. Program Visual Basic ini berfungsi untuk mengontrol 10 button pusher melalui arduino via komunikasi serial. Selain itu program ini juga untuk menayangkan video tampilan LCD peralatan SOGI via webcam. Program Visual Basic ini diawali dengan inisialisasi 10 tombol virtual button dan juga inisialisasi komunikasi serial ke arduino serta inisialisasi webcam. Lalu program Virtual Basic akan berjalan secara terus menerus selama komunikasi serial dalam kondisi available. Program Visual Basic akan membaca tombol virtual yang ditekan, lalu akan mengirimkan perintah ON ke pin output (button pusher) di arduino sesuai tombol virtual yang ditekan dan akan menayangkan video tampilan LCD peralatan SOGI.

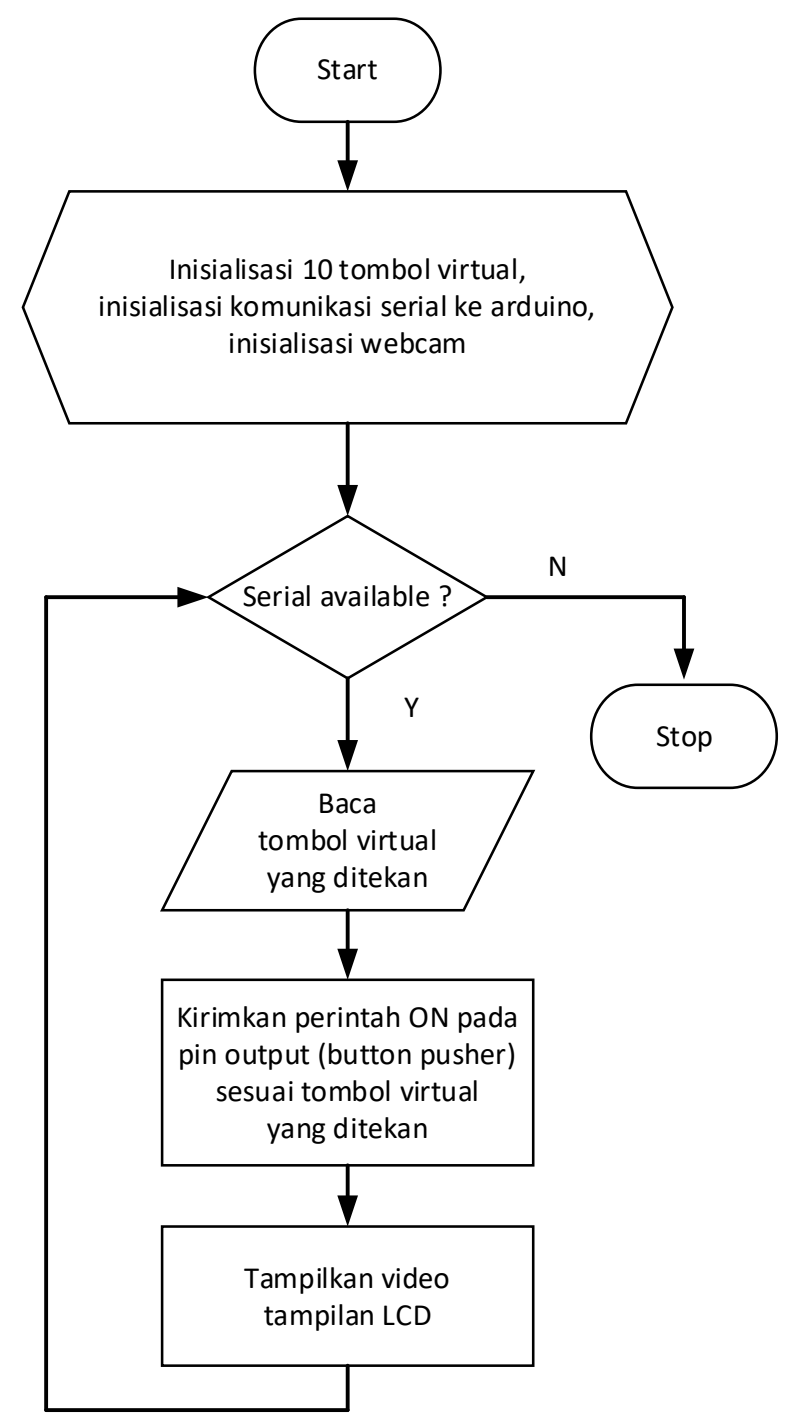

Gambar 4. Flowchart Program Visual Basic

\section{Hasil dan Pembahasan}

Peralatan SOGI memiliki tombol dan tampilan LCD. Pada saat praktik secara langsung (In Class Training), peserta pembelajaran dapat melakukan praktik secara langsung dengan cara menekan tombol dan melihat tampilan LCD peralatan SOGI. Sedangkan untuk praktik SOGI jarak jauh, peserta berada di lokasinya masing-masing (di luar UPDL Semarang), melakukan remote desktop ke komputer yang ada di laboratorium UPDL Semarang. Komputer di laboratorium SCADA UPDL Semarang sudah dipasang aplikasi Visual Basic, yang berkomunikasi dengan arduino secara serial, di mana arduino inilah yang akan mengontrol button pusher untuk menekan tombol-tombol yang ada di 
peralatan SOGI. Jumlah button pusher yang digunakan adalah sejumlah tombol peralatan SOGI yang mau dikontrol secara jauh jauh yaitu sebanyak 10 buah. Sedangkan untuk melihat tampilan LCD peralatan SOGI secara jarak jauh, menggunakan webcam. Tombol virtual dan video tampilan LCD peralatan SOGI, akan ditampilkan pada komputer UPDL Semarang menggunakan program Visual Basic, di mana pada komputer tersebut juga diinstall software remote desktop (anydesk). Para peserta pembelajaran jarak jauh akan melakukan praktik jarak jauh menggunakan komputernya masing-masing yang sudah diinstall dengan software remote desktop (anydesk). Peserta pembelajaran akan terkoneksi ke komputer yang ada di laboratorium SCADA UPDL Semarang melalui internet via software remote desktop tersebut, sehingga para peserta pembelajaran dapat melakukan praktik SOGI jarak jauh dari tempatnya masing-masing.

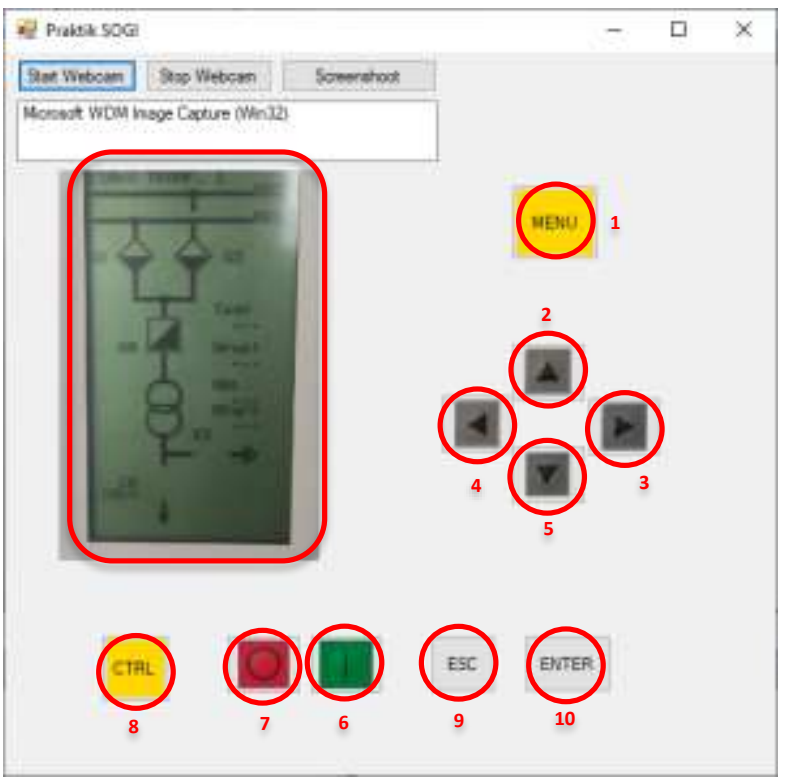

Gambar 5. Tampilan Aplikasi Visual Basic untuk Praktik SOGI Jarak Jauh

Gambar 5 merupakan gambar tampilan aplikasi Visual Basic untuk praktik SOGI jarak jauh. Tampilannya terdiri dari tombol virtual, dan video. Tombol virtual ada 10 buah yaitu : 1.MENU, 2.UP, 3.RIGHT, 4.LEFT, 5.DOWN, 6.CLOSE， 7.OPEN, 8.CTRL, 9.ESC, 10.ENTER. Sedangkan video akan menayangkan tampilan LCD peralatan SOGI secara real time.

Desain seperti pada gambar 2, telah diujicobakan di laboratorium SCADA UPDL Semarang, di mana yang melakukan uji coba / praktik berada di luar UPDL Semarang menggunakan remote desktop (anydesk) dengan koneksi internet. Setelah berhasil masuk ke anydesk maka dilanjutkan untuk menjalankan aplikasi Visual Basic. Lalu dilakukan pengujian untuk semua fungsi yaitu 10 tombol virtual dan 1 tampilan video. Hasil pengujian dapat dilihat pada tabel 1 di bawah ini. Pengujian ini diujicobakan beberapa kali untuk peserta yang berbeda lokasinya
Tabel 1. Hasil Uji Fungsi

\begin{tabular}{llc}
\hline NO. & \multicolumn{1}{c}{ PENGUJIAN } & HASIL \\
\hline 1. & Tombol MENU & OK \\
2. & Tombol UP & OK \\
3. & Tombol RIGHT & OK \\
4. & Tombol LEFT & OK \\
5. & Tombol DOWN & OK \\
6. & Tombol CLOSE (O) (merah) & OK \\
7. & Tombol OPEN (I) (hijau) & OK \\
8. & Tombol CTRL & OK \\
9. & Tombol ESC & OK \\
10. & Tombol ENTER & OK \\
11. & Tampilan Video & OK \\
\hline
\end{tabular}

\section{Kesimpulan}

Berdasarkan hasil uji coba yang telah dilakukan, maka dapat disimpulkan bahwa aplikasi arduino dan remote desktop ini dapat bekerja dengan tingkat keberhasilan $100 \%$ untuk semua fungsi yaitu 10 tombol dan 1 tampilan video. Dengan demikian metode praktik jarak jauh menggunakan aplikasi arduino dan remote desktop ini dapat diterapkan untuk pembelajaran praktik SOGI (Sistem Otomasi Gardu Induk) di UPDL Semarang, dan dapat dikembangkan lebih lanjut untuk pembelajaran lainnya di PT PLN (Persero).

\section{Referensi}

[1]. PLN; Susunan organisasi dan formasi jabatan PT PLN (Persero) Unit Pelaksana Pendidikan dan Pelatihan Semarang (Academy) Pada PT PLN (Persero) Pusat Pendidikan dan Pelatihan (Corporate University). 2018

[2]. Séamus C. McLoone; John Maloco. A A cost-effective hardware-based laboratory solution for demonstrating PID control. 2016; IEEE UKACC 11th International Conference on Control (CONTROL).

[3]. Christos Y Foulis; Simira Papadopoulou. A Portable Low-Cost Arduino-Based Laboratory Kit for Control Education. 2018; IEEE UKACC 12th International Conference on Control (CONTROL).

[4]. Lorraine M. Herger;Mercy Bodarky. Engaging students with open source technologies and Arduino. 2015; IEEE Integrated STEM Education Conference

[5]. Jen-Hsing Li. Control System Laboratory with Arduino. 2018; IEEE International Symposium on Computer, Consumer and Control (IS3C).

[6]. Anand Nayyar;Vikram Puri. A review of Arduino board's, Lilypad's \& Arduino shields. 2016; IEEE 3rd International Conference on Computing for Sustainable Global Development (INDIACom).

[7]. O. E. Amestica;P.E. Melin;C.R. Duran-Faundez;G.R. Lagos. An Experimental Comparison of Arduino IDE Compatible Platforms for Digital Control and Data Acquisition Applications. 2019; IEEE CHILEAN Conference on Electrical, Electronics Engineering, Information and Communication Technologies (CHILECON)

[8]. Maroš Pataky;Peter Fecil'ak. Remote Arduino programming with Blockly web interface. 2019; International Conference on Computing, Electronics \& Communications Engineering (iCCECE) 
[9]. Ahmad Adamu Galadima. Arduino as a learning tool 2014; 11th International Conference on Electronics, Computer and Computation (ICECCO)

[10]. Minghao Jiang; Gaopeng Gou; Junzheng Shi; Gang Xiong, I Know What You Are Doing With Remote Desktop. 2019; IEEE 38th International Performance Computing and Communications Conference (IPCCC)

[11]. Sashank Sridhar;Sowmya Sanagavarapu;S. Chitrakala. Cross-Platform Remote Desktop Sharing with IP Tunneling. 2020; IEEE 11th International Conference on Computing, Communication and Networking Technologies (ICCCNT).

[12]. Nikita M. Danchenko;Grigoriy A. Mazurenko. Detecting and analysis malicious activity on remote desktop protocols using integrated security system. 2018; IEEE Conference of Russian Young Researchers in Electrical and Electronic Engineering (EIConRus).
[13]. V. C. Reis; M. F. Santos; M. J. Carmo; F. C. Ferreira. Control of level systems by arduino via PC platform. 2016; IEEE 20th International Conference on System Theory, Control and Computing (ICSTCC).

[14]. Robert Repnik;Peter Bernad;Marjan Krašna. Teaching physics using programming of simulations. 2020; IEEE 43rd International Convention on Information, Communication and Electronic Technology (MIPRO)

[15]. A. Garrigós;D. Marroquí;J. M. Blanes;R. Gutiérrez;I. Blanquer;M. Cantó. Designing Arduino electronic shields: Experiences from secondary and university courses. 2017; IEEE Global Engineering Education Conference (EDUCON) 